\title{
A Study of Effects of Open Ceremony on e-learning Account Sustainability
}

\author{
L.H. Kuo, H.J. Yang \& L.M. Chen ${ }^{a}$ \\ National Kaohsiung Normal University, Taiwan, R.O.C.
}

\begin{abstract}
The purpose of this study was to identify whether an open ceremony affects on-line learning platform account keeping behavior. This is a longitudinal non-experimental study. Total 9959 user accounts on a e-learning server since 2009 were reviewed. The server provides on-line learning courses to the publics. There are two types of courses, one with open ceremony for learners in classroom and the other is not. A survival analysis was performed to assess the effectiveness of the ceremony for user account sustainability. It was found that after five years, the survival rate of ceremony group is 0.53 and non-ceremony group is 0.01 . Based upon the statistically significant effect, it was concluded that open ceremony had shown effects on user account sustainability.
\end{abstract}

\section{Introduction}

E-learning, Open-Courses, \& Platforms

In this information age, information system provides a flexible communication solution. It also plays an important way for supporting personal learning by establishing well organized educational environment.

E-learning had become a foundation of life-long learning. No matter when, or where, one can always rely on e-learning to exploring knowledge according one's will. E-learning provides a new concept on learning.

Open-course is another break though on the other side of e-learning. Open-courses are well organized learning activities and freely open to the publics. Based upon the concept of e-learning on the learner side, open-courses on the content side, and internet connected platform, a fully functional education environment is established. A conceptual model is illustrated in Figure 1.

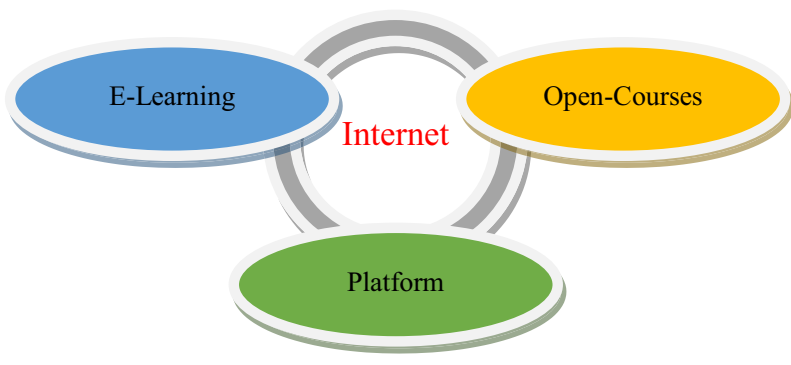

Figure 1. A fully functional education environment

\footnotetext{
$\overline{{ }^{\mathrm{a}} \text { Corresponding author: Li-Min Chen }}<$ chenlm7@gmail.com>
}

\subsection{Problem Statement}

For managing an information system, there is always a need to understand user's behavior on system service. In an open learning environment, how an information service provider can keep their users on using service is an important problem.

The purpose of this study was to identify whether an open ceremony affects on-line learning platform account keeping behavior.

\section{Literature review}

\subsection{Massive Open Online Courses}

A MOOC is an online educational platform that provides the dissemination of content to large numbers of users who have access to the Internet. The fundamental design of a MOOC affords users the ability to watch videos, access assignments, utilize resources, and connect with fellow users and instructors. Some MOOCs require users to complete tests and quizzes that can be automatically graded, while others rely on peer reviewed feedback from other current users.

Most MOOCs are free but do not provide transferable credit to other institutions. Some institutions do provide users the ability to obtain a "certificate of completion" by completing a final exam or standardized assignments, but this credential is not transferable as college-level credit. Recently, the American Council on Education accredited five MOOCs for which users can earn transferable credit. These courses require that students pay a fee and 
successfully complete assignments and exams before being awarded credit.

Several companies, organizations, and institutions support MOOCs and opensource education to users. As of January 2013, Coursera, Udacity, and edX were the three leading organizations to provide online platforms for MOOCs(Coursera, 2013).

\section{Methodology}

\subsection{Survival / Failure Analysis}

Survival/failure analysis is a family of techniques dealing with the time it takes for something to happen: a cure, a failure, an employee leaving, a relapse, a death, and so on.

One interesting feature of the analysis is that survival time (the DV) often is unknown for a number of cases at the conclusion of the study. Some of the cases are still in the study but have not yet failed: some employees have not yet left, some components are still functioning, some patients are still apparently well, or some patients are still living. For other cases, the outcome is simply unknown because they have withdrawn from the study or are for some reason lost to follow-up. Cases whose DV valuessurvival time - are unknown for whatever reasons are referred to as censored.

The term survival analysis is based on medical applications in which time to relapse or death is studied between groups who have received different medical treatments. Is survival longer for a group receiving ceremony rather than another?

\subsection{Life tables}

Within the family of survival- analysis techniques, different procedures are used depending on the nature of the data and the kinds of questions that are of greatest interest.

Life tables describe the survival (or failure) times for cases, and often are accompanied by a graphical representation of the survival rate as a function of time, called a survivor function. Survivor functions are frequently plotted side-by-side for two or more groups (e.g., treated and untreated patients) and statistical tests are used to test the differences between groups in survival time.

\subsection{Proportions Surviving at Various Time}

The primary goal of one type of survival analysis is to describe the proportion of cases surviving at various times, within a single group or separately for different groups. The analysis extends to statistical tests of group differences. The primary goal of the other type of survival analysis is to assess the relationship between survival time and a set of covariates (predictors), with treatment considered one of the covariates, to determine whether treatment differences are present after statistically controlling for the other covariates. We may ask that what the survival rate at various points in time is.

\subsection{Group Differences in Survival}

This study also asks that If there are different groups, are their survival rates different? Several tests are available to evaluate group differences. If statistically significant group differences are found, separate life tables and survivor functions are developed for each group.

\subsection{Limitations to survival Analysis}

One problem with survival analysis is the nature of the outcome variable, time itself. Events must occur before survival or failure time can be analyzed: Components must fail, users must leave, and patients must succumb to the illness. However, the purpose of treatment often is to delay this occurrence or prevent it altogether. The more successful the treatment, then, the less able the researcher is to collect data in a timely fashion.

Survival analysis is subject to the usual cautions about causal inference.

\subsection{Fundamental Equations for Survival Analysis}

Life tables are built around time intervals; in this study, the intervals are of width 3 months. The survivor function, $\mathrm{P}$, is the cumulative proportion of cases surviving to the beginning of the $i+1$ st interval, estimated as:

$$
P_{i+1}=p_{i} P_{i}
$$

where:

$$
\begin{aligned}
& p_{i}=1-q_{i} \\
& q_{i}=\frac{d_{i}}{r_{i}}
\end{aligned}
$$

and

where $d_{i}=$ number responding (dropping out) in the interval and

$$
r_{i}=n_{i}-\frac{1}{2} c_{i}
$$

where $n_{i}=$ number entering the interval $c_{i}=$ number censored in the interval (lost to follow up for reasons other than dropping out).

The proportion of cases surviving to the $(i+1) s t$ interval is the proportion who survived to the start of ith interval times the probability of surviving to the end of the ith interval. 


\section{Findings}

\subsection{Descriptive Statistics}

In Table 1., the months of account sustainability was listed. The minimum is four months and the maximum is fifty months. The average account sustains 34.9 months. The standard deviations are 15.271 months. The total accounts are 9959.
Table 1. N, Minimum, Maximum, Mean, \& Std. Deviation of Account Sustainability (Months)

\begin{tabular}{|c|c|c|c|c|c|}
\hline \multicolumn{6}{|c|}{ Descriptive Statistics } \\
\hline & $\mathrm{N} \mathrm{I}$ & Minimum & Maximum & Mean & $\begin{array}{ll}\text { Std. Devia- } \\
\text { tion }\end{array}$ \\
\hline MONTHS & 9959 & 4 & 50 & $\begin{array}{ll} & 34 . \\
0 & \end{array}$ & 15.271 \\
\hline Valid N (listwise) & 9959 & & & & \\
\hline
\end{tabular}

Table 2. Life table of account sustainability

\begin{tabular}{|c|c|c|c|c|c|c|c|c|c|c|c|c|c|}
\hline First-order Controls & Interval Start Time & $\begin{array}{l}\text { Number } \\
\text { Entering } \\
\text { Interval }\end{array}$ & $\begin{array}{c}\text { Number } \\
\text { Withdrawing } \\
\text { during Interval }\end{array}$ & $\begin{array}{l}\text { Number } \\
\text { Exposed to } \\
\text { Risk }\end{array}$ & $\begin{array}{l}\text { Number of } \\
\text { Terminal } \\
\text { Events }\end{array}$ & $\begin{array}{l}\text { Proportion } \\
\text { Terminating }\end{array}$ & $\begin{array}{c}\text { Proportion } \\
\text { Surviving }\end{array}$ & $\begin{array}{c}\text { Cumulative } \\
\text { Proportion } \\
\text { Sunviving at } \\
\text { End of Interval }\end{array}$ & $\begin{array}{l}\text { Std. Error of } \\
\text { Cumulative } \\
\text { Proportion } \\
\text { Surviving at } \\
\text { End of Interval }\end{array}$ & $\begin{array}{l}\text { Probability } \\
\text { Density }\end{array}$ & $\begin{array}{l}\text { Std. Error of } \\
\text { Probability } \\
\text { Density }\end{array}$ & Hazard Rate & $\begin{array}{l}\text { Std. Error of } \\
\text { Hazard Rate }\end{array}$ \\
\hline $\begin{array}{ll}\text { CEREMONY NON_CEREMONY } \\
\end{array}$ & 0 & 2402 & 0 & 2402.000 & 0 & .00 & 1.00 & 1.00 & .00 & .000 & .000 & .00 & .00 \\
\hline & 3 & 2402 & 0 & 2402.000 & 30 & .01 & .99 & .99 & .00 & .004 & .001 & .00 & .00 \\
\hline & 6 & 2372 & 0 & 2372.000 & 169 & .07 & .93 & .92 & .01 & .023 & .002 & .02 & .00 \\
\hline & 9 & 2203 & 0 & 2203.000 & 8 & .00 & 1.00 & .91 & .01 & .001 & .000 & .00 & .00 \\
\hline & 12 & 2195 & 0 & 2195.000 & 1072 & .49 & .51 & .47 & .01 & 149 & .003 & .22 & .01 \\
\hline & 15 & 1123 & 0 & 1123.000 & 20 & .02 & .98 & .46 & .01 & .003 & .001 & .01 & .00 \\
\hline & 18 & 1103 & 0 & 1103.000 & 25 & .02 & .98 & .45 & .01 & .003 & .001 & .01 & .00 \\
\hline & 21 & 1078 & 0 & 1078.000 & 23 & .02 & .98 & .44 & .01 & .003 & .001 & .01 & .00 \\
\hline & 24 & 1055 & 0 & 1055.000 & 437 & .41 & .59 & .26 & .01 & .061 & .003 & .17 & .01 \\
\hline & 27 & 618 & 0 & 618.000 & 18 & .03 & .97 & .25 & .01 & .002 & .001 & .01 & .00 \\
\hline & 30 & 600 & 0 & 600.000 & 20 & .03 & .97 & .24 & .01 & . 003 & .001 & .01 & .00 \\
\hline & 33 & 580 & 0 & 580.000 & 16 & .03 & .97 & .23 & .01 & .002 & .001 & .01 & .00 \\
\hline & 36 & 564 & 0 & 564.000 & 408 & .72 & .28 & .06 & .01 & .057 & .003 & .38 & .02 \\
\hline & 39 & 156 & 0 & 156.000 & 123 & .79 & .21 & .01 & .00 & .017 & .001 & .43 & .03 \\
\hline & 42 & 33 & 0 & 33.000 & 0 & .00 & 1.00 & .01 & .00 & .000 & .000 & .00 & .00 \\
\hline & 45 & 33 & 0 & 33.000 & 0 & .00 & 1.00 & .01 & .00 & .000 & .000 & .00 & .00 \\
\hline & 48 & 33 & 33 & 16.500 & 0 & .00 & 1.00 & .01 & .00 & .000 & .000 & .00 & .00 \\
\hline CEREMONY & 0 & 7557 & 0 & 7557.000 & 0 & .00 & 1.00 & 1.00 & .00 & .000 & .000 & .00 & .00 \\
\hline & 3 & 7557 & 0 & 7557.000 & 21 & .00 & 1.00 & 1.00 & .00 & .001 & .000 & .00 & .00 \\
\hline & 6 & 7536 & 0 & 7536.000 & 112 & .01 & .99 & .98 & .00 & .005 & .000 & .00 & .00 \\
\hline & 9 & 7424 & 0 & 7424.000 & 5 & .00 & 1.00 & .98 & .00 & .000 & .000 & .00 & .00 \\
\hline & 12 & 7419 & 0 & 7419.000 & 715 & .10 & .90 & .89 & .00 & .032 & .001 & .03 & .00 \\
\hline & 15 & 6704 & 0 & 6704.000 & 14 & .00 & 1.00 & .89 & .00 & .001 & .000 & .00 & .00 \\
\hline & 18 & 6690 & 0 & 6690.000 & 16 & .00 & 1.00 & .88 & .00 & . 001 & .000 & .00 & .00 \\
\hline & 21 & 6674 & 0 & 6674.000 & 16 & .00 & 1.00 & .88 & .00 & . 001 & .000 & .00 & .00 \\
\hline & 24 & 6658 & 0 & 6658.000 & 880 & .13 & .87 & .76 & .00 & .039 & . 001 & .05 & .00 \\
\hline & 27 & 5778 & 0 & 5778.000 & 12 & .00 & 1.00 & .76 & .00 & .001 & .000 & .00 & .00 \\
\hline & 30 & 5766 & 0 & 5766.000 & 13 & .00 & 1.00 & .76 & .00 & .001 & .000 & .00 & .00 \\
\hline & 33 & 5753 & 0 & 5753.000 & 11 & .00 & 1.00 & .76 & .00 & .000 & .000 & .00 & .00 \\
\hline & 36 & 5742 & 0 & 5742.000 & 1527 & .27 & .73 & .56 & .01 & .067 & .002 & .10 & .00 \\
\hline & 39 & 4215 & 0 & 4215.000 & 107 & .03 & .97 & .54 & .01 & . 005 & .000 & .01 & .00 \\
\hline & 42 & 4108 & 0 & 4108.000 & 43 & .01 & .99 & .54 & .01 & .002 & .000 & .00 & .00 \\
\hline & 45 & 4065 & 0 & 4065.000 & 18 & .00 & 1.00 & .54 & .01 & .001 & .000 & .00 & .00 \\
\hline & 48 & 4047 & 4019 & 2037.500 & 28 & .01 & .99 & .53 & .01 & .002 & .000 & .00 & .00 \\
\hline
\end{tabular}

Table 3. Frequency, \& Percent of accounts status

\begin{tabular}{|c|c|c|c|c|}
\hline \multicolumn{5}{|l|}{ N_USING } \\
\hline & Frequency & Percent & $\begin{array}{l}\text { Valid } \mathrm{P} \\
\text { cent }\end{array}$ & $\begin{array}{c}\text { Per-Cumulative } \\
\text { Percent }\end{array}$ \\
\hline ValidSTILL USING & 4052 & 40.7 & 40.7 & 40.7 \\
\hline $\begin{array}{l}\text { NOT US- } \\
\text { ING }\end{array}$ & 5907 & 59.3 & 59.3 & 100.0 \\
\hline Total & 9959 & 100.0 & 100 . & 0.0 \\
\hline
\end{tabular}

In Table 3, the frequency information of ceremony was illustrated. Those accounts with ceremony experience are $7559,75.9 \%$. Those who without ceremony experience are $2402,24.1 \%$.
Table 4. Frequency, \& Percent of Ceremonial Experience

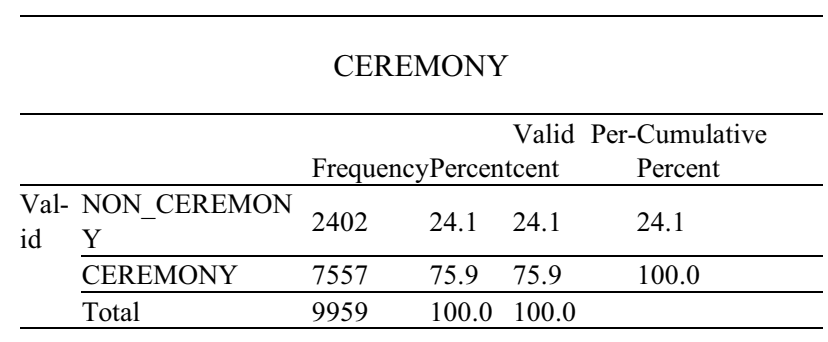

\subsection{Life table of account sustainability}

In Table 4., the intervals are width three months. The first-order controls are non-ceremony and ceremony. Items listed in Table 4. are number entering interval, number withdrawing during interval, number exposed to risk, number of terminal events, proportion terminating, proportion surviving, cumulative proportion surviving at 
end of interval, std. error of cumulative proportion surviving at end of interval, probability density, std. error of probability density, hazard rate, and std. error of hazard rate.

For the group without ceremony experience, there are 2,402 accounts in the beginning. In the first 15 months, the number drop less then half of the original, the number for the fifteenth months is 1,123 .

For the group with ceremony experience, there are 7,557 accounts in the beginning. Till the end of the fiftieth month, the value is still higher than half of the beginning. The value is 4,047 .

\subsection{Group Comparison}

In Table 5, the median survival time of non-ceremonial experience are 14.78 months and the median survival time of ceremonial experience are 48 months.

Table 5. Median survival time

\begin{tabular}{lll}
\hline \multicolumn{2}{l}{ Median Survival Time } & \\
\hline First-order Controls & Med Time \\
\hline CEREMONY & NON_CEREMONY & 14.78 \\
\cline { 2 - 3 } & CEREMONY & 48.00 \\
\hline
\end{tabular}

In Table 6, the significant level is lesser than .05 , the groups are significantly different by the log-rank test.

Table 6. Comparisons for factor ceremony status

\begin{tabular}{lcc}
\hline Overall Comparisons $^{\text {a }}$ & & \\
\hline Wilcoxon (Gehan) Statistic & df & Sig. \\
\hline 2860.997 & & .000 \\
\hline a. Comparisons are exact. & & \\
\hline
\end{tabular}

Figure 1, the survival function for cumulating survival rate by months was drawn. The dotted line was drawn according the ceremonial experience group.

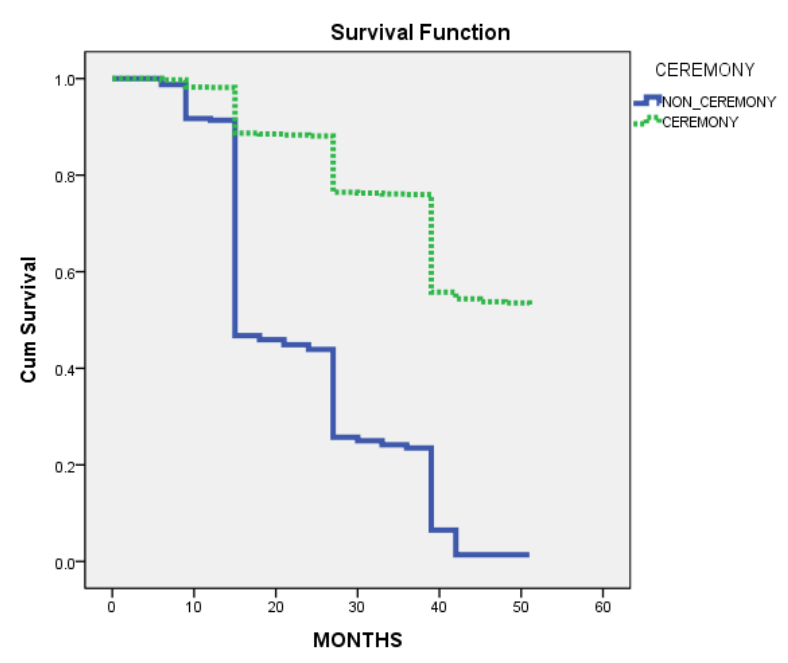

Figure 2. Survival Function

The solid line is for the non-ceremonial experience group.

In Table 7, the mean account sustainability was listed. The value of non-ceremony group is 20.53 months. The value of ceremony group is 39.47 months.

Table 7. N, Mean, Std. Deviation of Account Sustainability for both non-ceremony \& ceremony groups

\begin{tabular}{|c|c|c|c|c|c|c|c|c|}
\hline \multicolumn{9}{|l|}{ Descriptives } \\
\hline \multicolumn{9}{|l|}{ MONTHS } \\
\hline & & & & & $\begin{array}{l}95 \% \mathrm{C} \\
\text { Mean }\end{array}$ & lence Interv & & \\
\hline & & & & & Lower & Upper & & \\
\hline & $\mathrm{N}$ & Mean & Std. Deviation & Std. Error & Bound & Bound & Minimum & Maximum \\
\hline NON CEREMONY & 2402 & 20.53 & 11.140 & .227 & 20.08 & 20.97 & 4 & 50 \\
\hline CEREMONY & 7557 & 39.47 & 13.465 & .155 & 39.17 & 39.78 & 4 & 50 \\
\hline Total & 9959 & 34.90 & 15.271 & .153 & 34.60 & 35.20 & 4 & 50 \\
\hline
\end{tabular}

Table 8. One-way ANOVA for Comparing Account Sustainability of Groups

\begin{tabular}{|c|c|c|c|}
\hline \multicolumn{4}{|c|}{ ANOVA } \\
\hline \multicolumn{4}{|c|}{ MONTHS } \\
\hline & Sum of Squaresdf & Mean Square F & Sig. \\
\hline $\begin{array}{l}\text { Between } \\
\text { Groups }\end{array}$ & 654339.151 & $654339.151 \quad 3906.391$ & .000 \\
\hline $\begin{array}{l}\text { Within } \\
\text { Groups }\end{array}$ & $1667845.036 \quad 99$ & 167.505 & \\
\hline Total & $2322184.188 \quad 99$ & & \\
\hline
\end{tabular}

In Table 8, the result of comparing was significant. There exists significant difference between groups.

\section{Conclusions}

The purpose of this study was to identify whether an open ceremony affects on-line learning platform account keeping behavior. This is a longitudinal non-experimental study. Total 9959 user accounts on a e-learning server since 2009 were reviewed. The server provides on-line learning courses to the publics.

There are two types of courses, one with open ceremony for learners in classroom and the other is not. The mean value of non-ceremony group is 20.53 months. The mean value of ceremony group is 39.47 months. Based upon one-way ANOVA test, there is significant difference between ceremony group and non-ceremony. 
In the other words, the mean value of ceremony group is significantly higher than the mean value of non-ceremony group.

A survival analysis was performed to assess the effectiveness of the ceremony for user account sustainability. It was found that after five years, the survival rate of ceremony group is 0.53 and nonceremony group is 0.01 . Based upon the statistically significant effect, it was concluded that open ceremony had shown effects on user account sustainability.

This study was conducted from two view points. The first one is seeing accounts sustainability as a whole. The second one is based upon the time line. From both viewpoints, the conclusion is the same as "ceremony had shown significant effects on account sustainability."

\section{Reference}

1. COURSERA. 2013. Coursera website [Online]. Available: https://www.coursera.org [Accessed June 8 2015]. 